\title{
Raman scattering in sulphide glasses
}

\author{
I.D. Tolmachov ${ }^{1, *}$, A.V. Stronski ${ }^{1}$, H. Pribylova ${ }^{2}$, M. Vlček ${ }^{2}$ \\ ${ }^{1}$ V. Lashkaryov Institute of Semiconductor Physics, NAS of Ukraine, \\ 41, prospect Nauky, 03028 Kyiv, Ukraine \\ ${ }^{2}$ Faculty of Chemical Technology, University of Pardubice, \\ Studentská 573, 53210 Pardubice, Czech Republic, ${ }^{*}$ E-mail: tolmach_igor@mail.ru
}

\begin{abstract}
Raman spectra of two ternary glasses of composition $\mathrm{Ge}_{5} \mathrm{As}_{37} \mathrm{~S}_{58}$ and $\mathrm{As}_{4} \mathrm{Ge}_{30} \mathrm{~S}_{66}$ have been investigated. An influence of addition of third element on the spectra of binary glasses has been studied by comparison with spectra of two binary glasses of composition $\mathrm{Ge}_{33} \mathrm{~S}_{67}$ and $\mathrm{As}_{40} \mathrm{~S}_{60}$. Glass structure and phase separation effects are discussed.
\end{abstract}

Keywords: Raman scattering, chalcogenide glasses.

Manuscript received 24.09.10; accepted for publication 02.12.10; published online 30.12.10.

\section{Introduction}

Investigations of non-crystalline solids occupy one of the leading places in modern solid state physics. High research interest paid to these materials is caused by a number of their inherent properties (an opportunity to tailor continuously the composition and physical properties, effective production and treatment, stability in various media, etc.) which provide many opportunities for their practical applications. Studying of non-crystalline solid state is also of great importance from the viewpoint of the fundamental science. Chalcogenide vitreous semiconductors are very interesting materials of this class. Beside the mentioned physical properties inherent to glassy state, they have also many specific properties such as transparency in the infrared region of spectrum, a variety of photoinduced phenomena and high nonlinear optical properties, which made them very perspective in such practical applications as telecommunications, sensors, optical data storage, etc. Investigation of structure of these materials and it's relation to the composition and physical properties is a key for effective application. Raman scattering is one of the commonly used ways to investigate the structure of the glassy state. In this paper, we present the results of Raman spectroscopic studies concerning two ternary chalcogenide glasses of composition $\mathrm{Ge}_{5} \mathrm{As}_{37} \mathrm{~S}_{58}$ and $\mathrm{As}_{4} \mathrm{Ge}_{30} \mathrm{~S}_{66}$ and comparison with binary glasses $\mathrm{As}_{40} \mathrm{~S}_{60}$ and $\mathrm{Ge}_{33} \mathrm{~S}_{67}$.

\section{Experimental}

Glasses of compositions $\mathrm{As}_{40} \mathrm{~S}_{60}, \mathrm{Ge}_{5} \mathrm{As}_{37} \mathrm{~S}_{58}, \mathrm{Ge}_{33} \mathrm{~S}_{67}$ and $\mathrm{As}_{4} \mathrm{Ge}_{30} \mathrm{~S}_{66}$ were synthesized by direct melting of initial high purity elements in evacuated silica ampoules. $\mathrm{Ge}_{33} \mathrm{~S}_{67}$ and $\mathrm{As}_{4} \mathrm{Ge}_{30} \mathrm{~S}_{66}$ glasses were held at $750{ }^{\circ} \mathrm{C}$ for
$5 \mathrm{~h}$ and then melted at $800-970{ }^{\circ} \mathrm{C}$ for $10-12 \mathrm{~h}$. $\mathrm{As}_{40} \mathrm{~S}_{60}$ and $\mathrm{Ge}_{5} \mathrm{As}_{37} \mathrm{~S}_{58}$, glasses were melted at $650-$ $800{ }^{\circ} \mathrm{C}$ for $8-24 \mathrm{~h}$. After synthesis, the ampoules with melts were quenched in cold water. Raman spectra were investigated using IR Fourier spectrophotometer Bruker IFS55 Equinox with FRA-106 attachment. Nd-YAG laser light with the wavelength $1.064 \mu \mathrm{m}$ was used for excitation.

\section{Results and discussion}

Raman spectra of binary glasses $\mathrm{As}_{40} \mathrm{~S}_{60}$ and $\mathrm{Ge}_{33} \mathrm{~S}_{67}$ are presented in Figs $1 \mathrm{a}$ and $1 \mathrm{~b}$, respectively. The spectrum of $\mathrm{As}_{40} \mathrm{~S}_{60}$ glass consists of the main band centered at $344 \mathrm{~cm}^{-1}$ and a broad band in the lower frequency region $\left(50-250 \mathrm{~cm}^{-1}\right)$. There is also a weak band at $497 \mathrm{~cm}^{-1}$. The spectrum of $\mathrm{Ge}_{33} \mathrm{~S}_{67}$ glass contains the main peak at $344 \mathrm{~cm}^{-1}$ with the shoulder at $372 \mathrm{~cm}^{-1}$, which is usually referred to as $\mathrm{A}_{1}{ }^{\mathrm{c}}$ "companion" mode. Also, there is the distinguished peak at $436 \mathrm{~cm}^{-1}$ and weak band at $488 \mathrm{~cm}^{-1}$. In the lower frequency region $\left(50-250 \mathrm{~cm}^{-1}\right)$, there is a broad band with features at $85,117,154,208 \mathrm{~cm}^{-1}$.

The Raman spectrum of $\mathrm{As}_{4} \mathrm{Ge}_{30} \mathrm{~S}_{66}$ glass is presented in Fig. 2a. The higher frequency region (300$600 \mathrm{~cm}^{-1}$ ) contains the broad band with two maxima near 346 and $435 \mathrm{~cm}^{-1}$. This band can be deconvoluted into four Gaussian bands centered at 346, 375, 403 and $435 \mathrm{~cm}^{-1}$, as shown in Fig. 1. There is also a weak band at $495 \mathrm{~cm}^{-1}$ in this region.

The lower frequency part of the spectrum (50 $300 \mathrm{~cm}^{-1}$ ) also can be deconvoluted into Gaussian bands centered at $88,114,152,186,210$ and $246 \mathrm{~cm}^{-1}$ (see Fig. 2). 


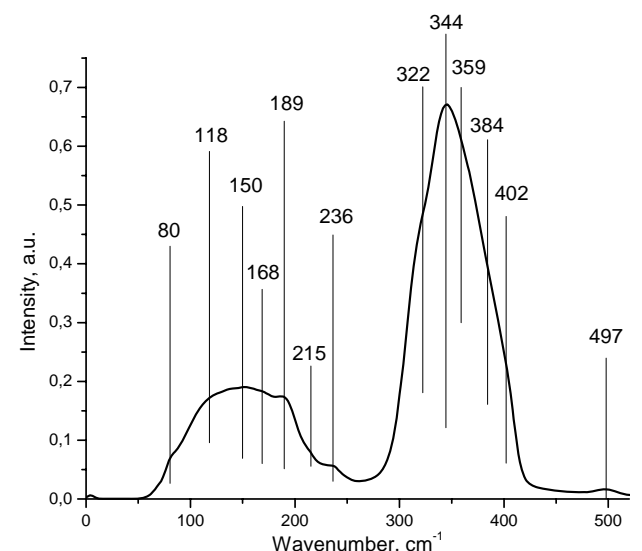

a

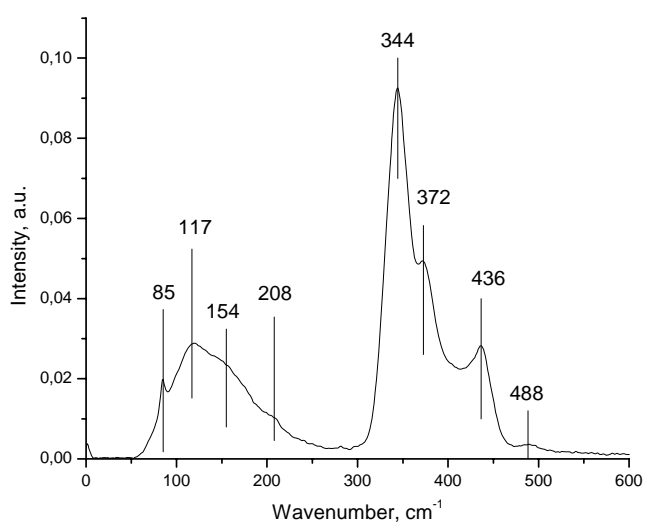

$\mathrm{b}$

Fig. 1. Raman spectra of binary glasses $\mathrm{As}_{40} \mathrm{~S}_{60}$ (a) and $\mathrm{Ge}_{33} \mathrm{~S}_{67}(\mathrm{~b})$.

In Fig. 2b, the Raman spectrum of $\mathrm{Ge}_{5} \mathrm{As}_{37} \mathrm{~S}_{58}$ glass is presented. There is a broad band centered near $343 \mathrm{~cm}^{-1}$ in the higher frequency region $\left(260-500 \mathrm{~cm}^{-}\right.$ $\left.{ }^{1}\right)$. Deconvolution of this band leads to five Gaussianshaped lines (see Fig. 2) with the maxima at 320, 167, 189,214 and $237 \mathrm{~cm}^{-1}$. There is also a weak band at $496 \mathrm{~cm}^{-1}$.

In the lower frequency region $\left(60-260 \mathrm{~cm}^{-1}\right)$ there is a broad band which has local peculiarities at 150,167 , 189,214 and $237 \mathrm{~cm}^{-1}$.

The most intensive band in the spectrum of $\mathrm{Ge}_{33} \mathrm{~S}_{67}$ glass is located at $344 \mathrm{~cm}^{-1}$. In the case of $\mathrm{As}_{4} \mathrm{Ge}_{30} \mathrm{~S}_{66}$ glass, it is shifted towards $346 \mathrm{~cm}^{-1}$. This band has been previously observed in binary glasses of $\mathrm{Ge}-\mathrm{S}$ system either of stoichiometric or non-stoichiometric composition [1-5]. The peak at $346 \mathrm{~cm}^{-1}$, as usually accepted, corresponds to the $\mathrm{A}_{1}$ symmetric stretching vibrations in the main structural units of the glass $\mathrm{Ge}\left(\mathrm{S}_{1 / 2}\right)_{4}$ tetrahedra, and in the case of ternary
$\mathrm{As}_{4} \mathrm{Ge}_{30} \mathrm{~S}_{66}$ system, it also contains a contribution from symmetrical vibrations of $\mathrm{As}\left(\mathrm{S}_{1 / 2}\right)_{3}$ pyramidal units [6]. Two other bands $-\mathrm{A}_{1}{ }^{\mathrm{c}}$ companion mode at $375 \mathrm{~cm}^{-1}$, and the band near $435 \mathrm{~cm}^{-1}$ have been also observed in $\mathrm{Ge}_{\mathrm{x}} \mathrm{S}_{1-\mathrm{x}}$ glasses of different compositions, but their origin still remains controversial.

Authors of the paper [7] associated the band $375 \mathrm{~cm}^{-1}$ with the presence of medium range order structures in these glasses. A model was assumed, according to which, glassy $\mathrm{Ge}(\mathrm{S}, \mathrm{Se})_{2}$, as opposed to $\mathrm{SiO}_{2}$, are formed not by a three-dimensional random network, but have rather layer-like structure consisted of medium-range order regions. The typical scale of these structures is about 10 to $20 \AA$.
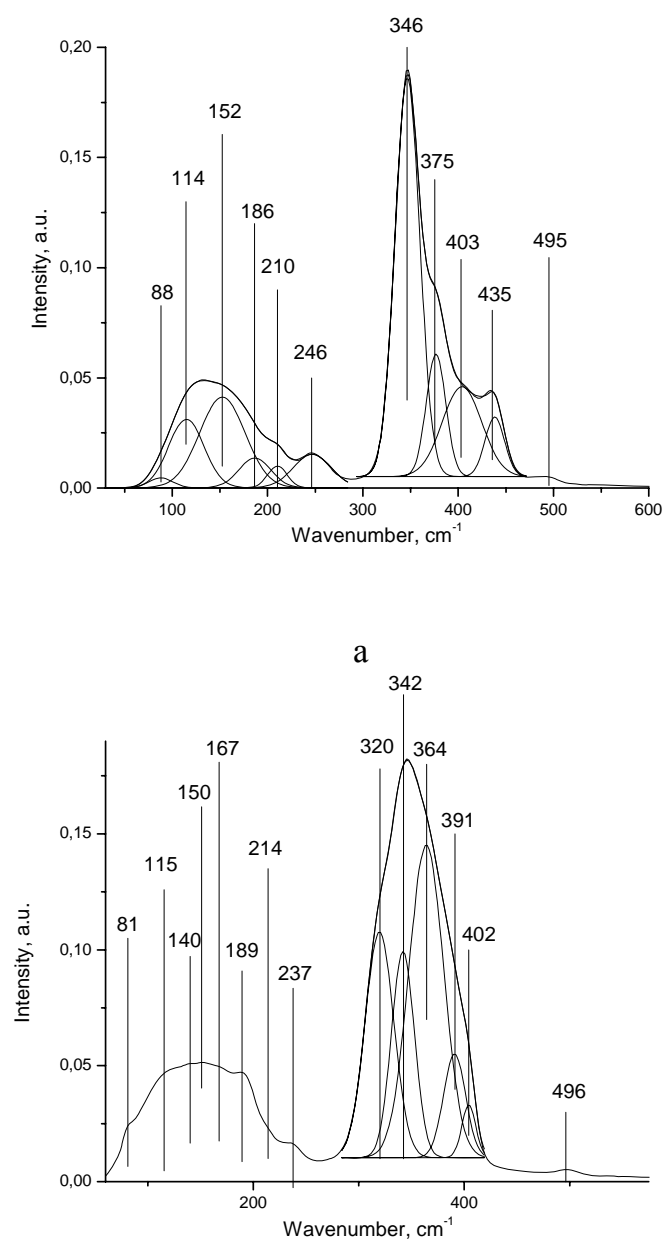

b

Fig. 2. Raman spectra of ternary glasses $\mathrm{Ge}_{30} \mathrm{As}_{4} \mathrm{~S}_{66}$ (a) and $\mathrm{Ge}_{5} \mathrm{As}_{37} \mathrm{~S}_{58}$ (b).

Authors of [3] investigated evolution of Raman spectra with temperature. They observed two stage crystallization of glassy $\mathrm{GeS}_{2}$. It was found that the $\mathrm{A}_{1}{ }^{\mathrm{c}}$ mode is present in spectra during the rise of temperature 
and remains after the transition to 3D-crystalline state (at $\sim 750^{\circ} \mathrm{C}$ ), and also it is present at temperatures higher than $850^{\circ} \mathrm{C}$ as a shoulder (when the transition to the 2Dcrystalline state occurs). After slow cooling down to room temperature, material retains $2 \mathrm{D}$-crystalline structure that also has the $\mathrm{A}_{1}{ }^{\mathrm{c}}$ mode in its spectrum. Therefore, by analogy with the 2D-crystalline state, the $\mathrm{A}_{1}{ }^{\mathrm{c}}$ mode in glassy $\mathrm{GeS}_{2}$ was ascribed to symmetrical vibrations of sulphur bridge atoms in edge-shared tetrahedra.

Authors of [5] provided comparison of Raman spectra of glassy $\mathrm{GeS}_{2}$ obtained under different quenching temperatures and cooling rates. A conclusion has been drawn that $\mathrm{A}_{1}{ }^{\mathrm{c}}$ mode together with $433 \mathrm{~cm}^{-1}$ band can be ascribed to vibrations in edge-shared tetrahedra. In paper [3], $433 \mathrm{~cm}^{-1}$ band was ascribed to the stretching vibrations of $\mathrm{S}-\mathrm{S}$ bonds that were either present separately in glass matrix or bond together with tetrahedral elements. This opinion is supported by the authors of [8]. They stated that the $434 \mathrm{~cm}^{-1}$ band that was observed by them in germanium sulphide films, corresponds to the vibrations of $\mathrm{S}-\mathrm{S}$ bonds interconnecting $\mathrm{Ge}\left(\mathrm{S}_{1 / 2}\right)_{4}$ tetrahedra. Authors of [3] claims that the presence of such bonds in stoichiometric glass indicates the presence of homopolar $\mathrm{Ge}-\mathrm{Ge}$ bonds. The band at $260 \mathrm{~cm}^{-1}$, the intensity of which was growing up with the increase of Ge concentration was ascribed to the presence of these bonds. The authors, however, didn't explain why the intensity of $433 \mathrm{~cm}^{-1}$ band (along with $\mathrm{A}_{1}{ }^{\mathrm{c}}$ band) decreases with increasing of the sulphur content.

Authors of [5] don't support the assumption about the presence of homopolar bonds in glassy $\mathrm{GeS}_{2}$. The bands at 200, 237 and $256 \mathrm{~cm}^{-1}$ which were observed in samples of glassy $\mathrm{GeS}_{2}$ obtained at different synthesis conditions, were ascribed to the vibrations in three-fold coordinated structures consisted of $\mathrm{Ge}$ and $\mathrm{S}$ atoms, for instance, to the vibrations in crystalline nanophase cGeS. As mentioned in [5], c-GeS nanoparticles with sizes about 7-12 $\AA$ may exist in the glass structure, or, depending on the synthesis conditions, may form larger c-GeS particles within the matrix of glassy $\mathrm{GeS}_{2}$.

In the paper [4], the band near $440 \mathrm{~cm}^{-1}$ that was observed in glasses of nearly stoichiometric compositions $\mathrm{Ge}_{\mathrm{x}} \mathrm{S}_{1-\mathrm{x}}$, was ascribed to the $\mathrm{F}_{2}$ mode of tetrahedra $\mathrm{Ge}\left(\mathrm{S}_{1 / 2}\right)_{4}$. In paper [9], the structure of $\mathrm{As}_{4} \mathrm{Ge}_{30} \mathrm{~S}_{66}$ glass was investigated by means of X-ray diffraction. By comparison of experimental results with those of numerical simulation, a conclusion was drawn that the structure of glass is given by inhomogeneous network with regions expressing a quasi-layer type stacking interlinked with regions of random network where the amount of homopolar bonds is kept minimum.

The $495 \mathrm{~cm}^{-1}$ band observed in the spectrum of $\mathrm{As}_{4} \mathrm{Ge}_{30} \mathrm{~S}_{66}$ is characteristic for the presence of $\mathrm{S}-\mathrm{S}$ bonds. Presence of these bonds implies the existence of edge-shared $\mathrm{Ge}\left(\mathrm{S}_{1 / 2}\right)_{4}$ tetrahedra in the structural backbone of the glass, which must lead to the appearance of redundant $\mathrm{S}$ atoms.
The $246 \mathrm{~cm}^{-1}$ band was observed earlier in the $\mathrm{Ge}_{\mathrm{x}} \mathrm{A}_{40-\mathrm{x}} \mathrm{S}_{60}$ glass spectra [10]. When $\mathrm{x}=0$, a weak band near $231 \mathrm{~cm}^{-1}$ was observed, which was growing and shifting towards the higher frequencies with increasing $\mathrm{x}$ until $245 \mathrm{~cm}^{-1}$ when $\mathrm{x}=36$. This feature was related by authors with increasing amount of homopolar $\mathrm{Ge}-\mathrm{Ge}$ bonds compared to As-As. As claimed in [10], homopolar $\mathrm{Ge}-\mathrm{Ge}$ bonds are located in $\mathrm{Ge}-\mathrm{S}_{4-\mathrm{n}} \mathrm{Ge}_{\mathrm{n}}$ tetrahedra and/or in $\mathrm{Ge}_{2} \mathrm{~S}_{6 / 2}$ ethane-like clusters.

Similar peculiarity was observed in [11] during the investigation of series of compounds $\left(\mathrm{Ge}_{2} \mathrm{~S}_{3}\right)_{\mathrm{x}}\left(\mathrm{As}_{2} \mathrm{~S}_{3}\right)_{1-\mathrm{x}}$ where $0<x<1$. When $x>0.5$, the broad band centered at $250 \mathrm{~cm}^{-1}$ appeared and began to increase. As stated in [11], this band corresponds to the vibrations in ethane-like $\mathrm{Ge}_{2} \mathrm{~S}_{6}$ nanophase that segregates from $\mathrm{GeS}_{2}$. According to the results of calculations provided in [5], ethane-like nanophase possesses the intensive peak at $250 \mathrm{~cm}^{-1}$ and also several bands near $400 \mathrm{~cm}^{-1}$. In the decomposition of the main peak in the $\mathrm{As}_{4} \mathrm{Ge}_{30} \mathrm{~S}_{66}$ spectrum (see Fig. 2), there is a broad band centered at $403 \mathrm{~cm}^{-1}$. Therefore, bands at 246 and $403 \mathrm{~cm}^{-1}$ can be ascribed to the vibrations in ethane-like nanophase $\mathrm{Ge}_{2} \mathrm{~S}_{6}$.

In Fig. 3, the difference between spectra of $\mathrm{As}_{4} \mathrm{Ge}_{30} \mathrm{~S}_{66}$ and $\mathrm{Ge}_{33} \mathrm{~S}_{67}$ glasses normalized to the intensity of the main peak is shown. The difference spectra clearly reveal the changes made by addition of arsenic to the $\mathrm{Ge}_{33} \mathrm{~S}_{67}$ glass. The abrupt transition from minimum to maximum near $346 \mathrm{~cm}^{-1}$ is due to the red shift of the main band. The difference spectrum has maximum near $250 \mathrm{~cm}^{-1}$ corresponding to the appearance of this band in the spectrum of $\mathrm{As}_{4} \mathrm{Ge}_{30} \mathrm{~S}_{66}$ glass, and minima at 374 and $438 \mathrm{~cm}^{-1}$ due to the softening of corresponding bonds. The former peculiarity can be ascribed to the precipitation of ethanelike nanophase, while the latter to the decrease of the $\mathrm{Ge}\left(\mathrm{S}_{1 / 2}\right)_{4}$ tetrahedra concentration.

The Raman spectrum of $\mathrm{Ge}_{5} \mathrm{As}_{37} \mathrm{~S}_{58}$ glass (see Fig. 2b) is almost similar to the spectrum of binary $\mathrm{As}_{40} \mathrm{~S}_{60}$ glass. The main broad band in the spectra of $\mathrm{As}_{40} \mathrm{~S}_{60}$ and $\mathrm{Ge}_{5} \mathrm{As}_{37} \mathrm{~S}_{58}$ glasses at $342 \mathrm{~cm}^{-1}$ corresponds to the band characteristic for $\mathrm{As}_{\mathrm{x}} \mathrm{S}_{100-\mathrm{x}}$ glasses of different compositions. The bands at 321,343 and $361 \mathrm{~cm}^{-1}$ that are present in the decomposition of main band are typical to the $\mathrm{As}_{42} \mathrm{~S}_{58}$ glass enriched by arsenic as compared to the stoichiometric $\mathrm{As}_{40} \mathrm{~S}_{60}$ glass. The $342 \mathrm{~cm}^{-1}$ band, as generally accepted $[6,10,11]$, corresponds to the symmetric $v_{1}$ vibrations of pyramidal $\operatorname{As}\left(\mathrm{S}_{1 / 2}\right)_{3}$ units. The band at $361 \mathrm{~cm}^{-1}$ corresponds to the intensive mode of crystalline $\mathrm{As}_{4} \mathrm{~S}_{4}$ [6]. The increase in this band intensity is characteristic of $\mathrm{As}_{\mathrm{x}} \mathrm{S}_{1-\mathrm{x}}$ compositions when $\mathrm{x}>40$, that is arsenic enriched as compared to the stoichiometric glass $[6,12]$. Numerical calculations provided in [12] allow to ascribe the band at $361 \mathrm{~cm}^{-1}$ to the presence of $\mathrm{As}_{4} \mathrm{~S}_{4}$ clusters in material. In the lower frequency region of the $\mathrm{Ge}_{5} \mathrm{As}_{37} \mathrm{~S}_{58}$ spectrum, we can also see the bands observed earlier by the authors of [6] in the $\mathrm{As}_{42} \mathrm{~S}_{58}$ glass, in particular: the bands at 150 (corresponds to the $147 \mathrm{~cm}^{-1}$ band), 167, 189, 214 and $237 \mathrm{~cm}^{-1}$ (corresponds to the 
$234 \mathrm{~cm}^{-1}$ band). Bands at 150,167, 189 and $214 \mathrm{~cm}^{-1}$ can also be ascribed to the vibrations in $\mathrm{As}_{4} \mathrm{~S}_{4}$ clusters $[6,11]$.

The band near $496 \mathrm{~cm}^{-1}$ that is characteristic of S-S bonds appears in spectra of glass of either stoichiometric $\mathrm{As}_{40} \mathrm{~S}_{60}$ or non-stoichiometric $\mathrm{Ge}_{5} \mathrm{As}_{37} \mathrm{~S}_{58}$ glass with Ge additive. Thus, presence in the spectrum of $\mathrm{As}_{40} \mathrm{~S}_{60}$ glass bands at $361,150,167,189$ and $214 \mathrm{~cm}^{-1}$ that are characteristic of $\mathrm{As}_{4} \mathrm{~S}_{4}$ clusters, and the band at $496 \mathrm{~cm}^{-1}$, suggests the non-homogeneity and nanophase separation in stoichiometric glass.

In Fig. 4, the difference between spectra of $\mathrm{Ge}_{5} \mathrm{As}_{37} \mathrm{~S}_{58}$ and $\mathrm{As}_{40} \mathrm{~S}_{60}$ glasses normalized to the intensity of the main peak is shown. As can be seen from Fig. 4, introduction of $\mathrm{Ge}$ additives leads to appearance of the minima at 310 and $330 \mathrm{~cm}^{-1}$, which corresponds to the anti-symmetrical and symmetrical vibrations of $\mathrm{AsS}_{3}$ pyramids [6]. The positive peaks near 241, 383 and $408 \mathrm{~cm}^{-1}$ can be ascribed to the vibrations in ethane-like clusters that can be formed in glass with addition of Ge.

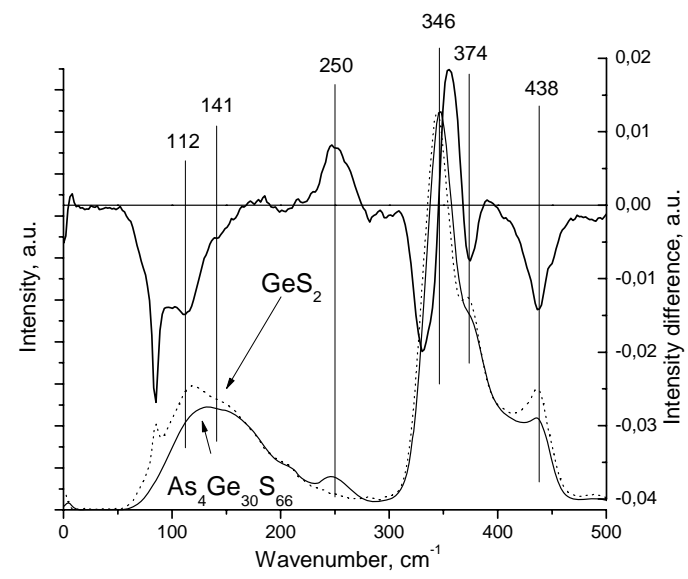

Fig. 3. Difference between spectra of $\mathrm{As}_{4} \mathrm{Ge}_{30} \mathrm{~S}_{66}$ and $\mathrm{Ge}_{33} \mathrm{~S}_{67}$ glasses normalized to the intensity of the main peak.

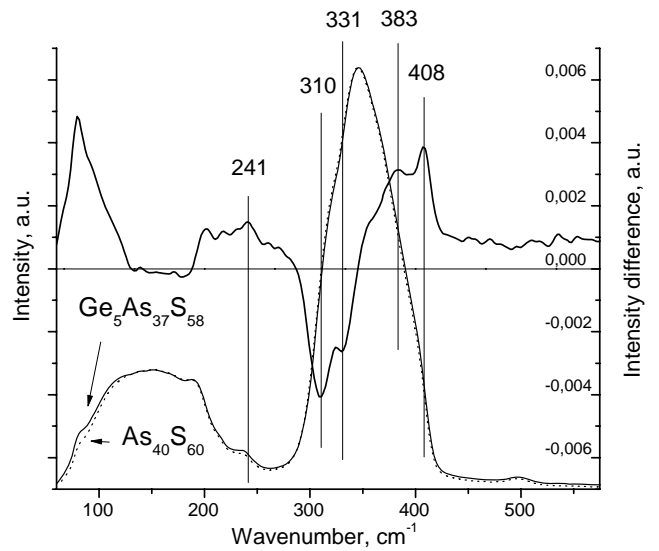

Fig. 4. Difference between spectra of $\mathrm{Ge}_{5} \mathrm{As}_{37} \mathrm{~S}_{58}$ and $\mathrm{As}_{40} \mathrm{~S}_{60}$ glasses normalized to the intensity of the main peak.

\section{Conclusions}

Raman spectra of two ternary glasses with compositions $\mathrm{Ge}_{5} \mathrm{As}_{37} \mathrm{~S}_{58}$ and $\mathrm{As}_{4} \mathrm{Ge}_{30} \mathrm{~S}_{66}$ have been investigated. An influence of third element addition on the spectra of binary glasses has been studied by comparison with two binary glasses of composition $\mathrm{Ge}_{33} \mathrm{~S}_{67}$ and $\mathrm{As}_{40} \mathrm{~S}_{60}$. The observed peaks in Raman spectra are characteristic either to the main elements forming structural backbone of the glasses (tetrahedral $\mathrm{Ge}\left(\mathrm{S}_{1 / 2}\right)_{4}$ units and pyramidal $\mathrm{As}\left(\mathrm{S}_{1 / 2}\right)_{3}$ units) or various inclusions (molecular $\mathrm{As}_{4} \mathrm{~S}_{4}$ clusters and ethane-like nanophase $\mathrm{Ge}_{2} \mathrm{~S}_{6 / 2}$ ). Inhomogeneity and nanophase separation can be observed in glasses of either non-stoichiometric or stoichiometric composition.

\section{References}

1. X. Feng, W.J. Bresser, P. Boolchand, Direct evidence for stiffness threshold in chalcogenide glasses // Phys. Rev. Lett. 78 (23), p. $4422-4425$ (1997).

2. Z. Cernosek, J. Holubova, E. Cernoskova, M. Frumar, Homogeneity threshold in sulphur rich Ge-S glasses // JOAM, 3(2), p. 459-462 (2001).

3. $\quad 3$. I.P. Kotsalas, C. Raptis, Structural Raman studies of $\mathrm{Ge}_{\mathrm{x}} \mathrm{S}_{1-\mathrm{x}}$ chalcogenide glasses // JOAM, 3(3), p. 675-684 (2001).

4. L. Cai, P. Boolchand, Nanoscale phase separation of $\mathrm{GeS}_{2}$ glass // Phil. Mag., 82(15), p. 1649-1657 (2002).

5. R. Holomb, P. Johansson, V. Mitsa, I. Rosola, Local structure of technologically modified $\mathrm{g}-\mathrm{GeS}_{2}$ : resonant Raman and absorption edge spectroscopy combined with ab initio calculations // Phil. Mag., 85 (25), p. 2947-2960 (2005). 
6. E.F. Venger, A.V. Melnichuk, A.V. Stronski, Photoinduced Phenomena in Chalcogenide Glassy Semiconductors and Their Practical Application. Akademperiodika, Kyiv, 2007 (in Russian).

7. P.M. Bridenbaugh, G.P. Espinosa, J.E. Grifiths, et al. // Phys. Rev. B, 20(10), p. 4140 (1979).

8. C.C. Huang, D.W. Hewak, Deposition and characterization of germanium sulphide glass planar waveguides // Optics Express, 12 (11), p. 2501-2506 (2004).

9. F. Sava, A. Anghel, I. Kaban, W. Hoyer, M. Popescu, Atomic scale structure of $\mathrm{Ge}_{30} \mathrm{As}_{4} \mathrm{~S}_{66}$ // JOAM, 7(4), p. 1971-1975 (2005).

10. E. Vateva, E. Skordeva, Nanoscale arrangement in the $\mathrm{Ge}_{\mathrm{x}} \mathrm{As}(\mathrm{Sb})_{40-\mathrm{x}} \mathrm{S}_{60}$ systems // JOAM, 4(1), p. 3-12 (2002).

11. S. Mamedov, D.G. Georgiev, Tao Qu, P. Boolchand, Evidence for nanoscale phase separation of stressed-rigid glasses // J. Phys.: Condens. Matter. 15, p. S2397-S2411 (2003).

12. R.M. Holomb, V.M. Mitsa, Simulation of Raman spectra of $\mathrm{As}_{\mathrm{x}} \mathrm{S}_{100-\mathrm{x}}$ glasses by the results of $\mathrm{ab}$ initio calculations of $\mathrm{As}_{\mathrm{n}} \mathrm{S}_{\mathrm{m}}$ clusters vibrations // JOAM, 6(4), p. 1177-1184 (2004). 